\title{
PARÂMETROS CURRICULARES NACIONAIS: UMA REVISITA AOS TEMAS TRANSVERSAIS MEIO AMBIENTE E SAÚDE
}

\author{
NATIONAL CURRICULUM PARAMETERS: REVISITING HEALTH AND ENVIRONMENT CROSS-CUTTING \\ ISSUES
}

\author{
Alexandre Maia do Bomfim ${ }^{1}$ \\ Maylta Brandão dos Anjos ${ }^{2}$ \\ Marcio Douglas Floriano ${ }^{3}$ \\ Carmen Simone Macedo Figueiredo ${ }^{4}$ \\ Denise Azevedo dos Santos ${ }^{5}$ \\ Carolina Luiza de Castro da Silva ${ }^{6}$
}

Resumo Nosso estudo parte do legado dos temas transversais deixado pelos Parâmetros Curriculares Nacionais, especificamente os de meio ambiente e saúde, procurando entender como foram processados em documentos oficiais - como as Diretrizes Curriculares Nacionais, as Orientações Curriculares para o Ensino Médio etc. - e como foram absorvidos e ressignificados no interior das escolas, principalmente nos projetos político-pedagógicos. Procurou-se problematizar esses temas com base no momento atual, sem desconsiderar, no entanto, o contexto em que foram criados. Para essa releitura, o suporte veio de autores que trabalham com análise de textos e pesquisa qualitativa. O estudo das partes 'meio ambiente' e 'saúde' mostrou que os textos, de maneira geral, são pouco atraentes; pouco práticos; apresentam dificuldades em dar pistas de ação; não mostram bem as diferentes interfaces com as diferentes áreas; não facilitam a visualização do sentido em que ocorre a trans e a interdisciplinaridade; apresentam-se em alguns momentos lacunares ou superficiais; e têm uma proposta de educação comportamentalista. Nesse limite, a educação serve mais à conformação do que à transformação da realidade; responsabiliza demasiadamente o indivíduo e isenta o Estado; promove uma cidadania passiva, que alcança a compreensão do direito, mas não a sua realização.

Palavras-chave educação ambiental; educação e saúde; temas transversais; PCNs; DCNs.
Abstract Our study begins with the legacy of the cross-cutting issues left by the National Curriculum Parameters, specifically concerning environment and health, in an attempt to understand how they were processed in official documents - such as the National Curriculum Guidelines, the Curriculum Instructions for Secondary Education, etc. - and how they were absorbed and resignified within the schools, particularly in the political-pedagogical projects. An attempt was made to problematize these topics based on the current moment, never neglecting, however, the context in which they were created. For this new reading, support came from authors working with text analysis and qualitative research. The study of the 'environment' and 'health' portions showed that the texts are largely unattractive; impractical; have difficulties in giving clues for action; do not show the different interfaces with the different areas well; do not facilitate viewing the direction in which trans and interdisciplinarity take place; at times, are insufficient or superficial, and bring a behaviorist proposal for education. Within these limitations, education is more useful for conformity than to actually transform reality; it attributes too much responsibility to the individual and exempts the State from its duties; it fosters passive citizenship, which indeed affords an understanding of one's rights, but does not actually achieve them.

Keywords environmental education; education and health; cross-cutting issues; NCPs; DCNs. 
Uma fase estrutural só pode ser concretamente estudada e analisada após ter superado todo o seu processo de desenvolvimento, não durante o próprio processo (...). (Gramsci, 1981, p. 118).

\section{A década neoliberal e a reforma conservadora da educação}

A segunda metade da década de 1990, no governo do presidente Fernando Henrique Cardoso (FHC), foi emblemática para a reorganização atual da estrutura educacional. São constituídos nesse período a principal lei educacional brasileira, a lei n. 9.394/1996 - Lei de Diretrizes e Bases da Educação Nacional, a chamada LDB (Brasil, 1996) -, os Parâmetros Curriculares Nacionais (PCNs) (Brasil, 1997a, 1997b) e as Diretrizes Curriculares Nacionais (DCNs) (Brasil, 1998c). Apesar das duras críticas que recebeu desde a sua criação (Saviani, 1997), a LDB tornou-se a principal referência para a organização da educação formal no Brasil, da educação infantil até o ensino superior. Desde a sua criação, seguiram-se a ela decretos, pareceres e orientações, mas a LDB, constituída na década neoliberal (Shiroma, Moraes e Evangelista, 2002), ${ }^{7}$ continua, apesar de suas contradições, a ser o ponto de partida para novas adequações ou reformulações para a organização educacional.

Nosso estudo se atém ao legado dos temas transversais, especificamente os de meio ambiente e saúde, deixado pelos PCNs. E sua proposta é de retomar esses temas, buscando entender como foram processados em diferentes documentos oficiais - DCNs, Orientações Curriculares para o Ensino Médio (OCEMs) etc. - e como foram absorvidos e ressignificados no interior das escolas, em seus projetos político-pedagógicos (PPPs).

Essa releitura contou com o aporte teórico advindo de autores como Orlandi (2005), que nos indicou, entre outros pontos, que a forma de tratar um texto é "referi-lo às suas condições de produção, estabelecer as relações que ele mantém com sua memória e também remetê-lo a uma formação discursiva - e não outra - para compreendermos o processo discursivo que indica (...)"(Orlandi, 2005, p. 42). ${ }^{8}$ De Karel Kosik, especificamente em seu trabalho menos lido, Dialética do concreto, vale citar a passagem: “O texto, porém, pode dizer alguma coisa diferente dos testemunhos, pode dizer mais, ou menos, (...) a intenção pode não se ter realizado ou ter sido ultrapassada, e no texto (na obra) há mais do que o autor pretendia" (Kosik, 1976, p. 141). Além disso, contamos com autores como Goldenberg (2003) e Maingueneau (1997), que nos proporcionaram uma incursão guiada dentro textos, em busca exatamente do que não é evidente na narrativa. 


\section{Um olhar sobre os temas transversais}

Foi o Ministério da Educação (MEC) que, por meio do documento “PCN: temas transversais" (Brasil, 1998d), da Secretaria de Educação Fundamental, incentivou que se conferisse atenção especial aos temas 'ética', 'saúde', 'meio ambiente', 'orientação sexual', 'pluralidade cultural', 'trabalho e consumo'. Propôs-se que tanto as escolas quanto os professores das diferentes disciplinas assumissem, de forma transdisciplinar, tais temáticas.

Por que essas temáticas e não outras? Por que são temas com abordagens mais amplas e, por isso, são inter ou transdisciplinares por excelência? Não seriam possíveis outros? E mais: refletindo-os para a atualidade, eles obtiveram êxito? Esses temas transversais continuam válidos? Há outros a serem incorporados? 'Segurança e violência', 'artes', 'política', 'desigualdade social' não poderiam ser incorporadas como exemplos de novos temas transversais?

Os temas transversais, na verdade, podem se tocar constantemente, além de estarem relacionados com vários outros temas; são inúmeras as fronteiras e as interfaces. A 'orientação sexual' toca no tema 'saúde'; este, no de 'meio ambiente'; e todos se relacionam com 'trabalho e consumo', assim como poderiam relacionar-se com 'ética', e esta com 'política' (mesmo em seu sentido estrito, de organização partidária ou de governo). Não obstante, a 'ética', por exemplo, um tema amplo, poderia dar conta de todos esses assuntos, dependendo do encaminhamento dado por um educador.

Na verdade, o que justifica um 'tema transversal' acaba sendo um contexto social, cultural e histórico. Assim, para não dizer que num tema transversal cabe qualquer coisa, ele será mais adequado quando prezado por boa parte da sociedade e justificado por um contexto, mesmo que não se relacione imediatamente com as diferentes disciplinas.

O corpo técnico que escolheu os temas transversais justificou a escolha com base em quatro critérios: urgência social; abrangência nacional; possibilidade de ensino e aprendizagem; e favorecimento à compreensão da realidade e à participação social (Brasil, 1998d). Para prosseguir, vale o alerta de Maingueneau:

É preciso, de uma maneira ou outra, considerar o modo de existência destes grupos que negam constantemente sua importância, ao se considerarem transparentes: fiéis zelosos, simples técnicos, representantes dos trabalhadores, consumidores etc., sempre se apresentam como portadores de mensagens (1997, p. 55).

Os temas transversais "tratam de processos que estão sendo intensamente vividos pela sociedade, pelas comunidades, pelas famílias, pelos alunos e educadores em seu cotidiano" (Brasil, 1998d, p. 26). 
De qualquer forma, o importante mesmo seria definir os temas transversais por meio de uma consulta popular. Eles até poderiam passar por um 'tratamento' feito por especialistas, porém precisariam justificar-se no coletivo. Tal processamento é provavelmente mais importante para os temas transversais do que para as disciplinas clássicas - resultantes de uma tradição e de démarches científicas.

Os documentos que constituem os PCNs (Brasil, 1997a, 1997b), de forma emblemática e categórica, procuraram fortalecer, a cada momento, a ideia de cidadania, presumidamente democrática. O propósito dos PCNs e seus temas transversais seria, então, uma 'educação para a cidadania' que pudesse oferecer compreensão e acesso a direitos e deveres sociais. Considerando as características distintas no âmbito da constituição de um sujeito soberano, fazemos mais uma pergunta: a própria construção dos PCNs garantiu esse ideal? Analisemos a passagem a seguir:

O processo de elaboração dos Parâmetros Curriculares Nacionais teve início a partir do estudo de propostas curriculares de estados e municípios brasileiros, da análise realizada pela Fundação Carlos Chagas sobre os currículos oficiais e do contato com informações relativas a experiências de outros países. (...) Formulou-se, então, uma proposta inicial que, apresentada em versão preliminar, passou por um processo de discussão em âmbito nacional, em 1995 e 1996, do qual participaram docentes de universidades públicas e particulares, técnicos de secretarias estaduais e municipais de Educação, de instituições representativas de diferentes áreas de conhecimento, especialistas e educadores. Desses interlocutores, foram recebidos aproximadamente setecentos pareceres sobre a proposta inicial, que serviram de referência para a sua reelaboração (Brasil, 1997a, p. 15, grifos nossos).

Antes de qualquer inferência, vale alertar que a passagem citada advém do documento mais amplo de apresentação dos PCNs (Brasil, 1997a) e não do documento específico sobre os temas transversais (Brasil, 1997b).

Para a análise que se segue, pode-se dar destaque às características dos primeiros momentos da construção dos PCNs: a identificação do intelectual orgânico ${ }^{9}$ institucional que inicia o processo, a Fundação Carlos Chagas, responsável pela versão preliminar dos PCNs; a influência advinda das experiências de outros países, conforme as pesquisas (nacionais e internacionais) trabalhadas naquele momento; o curto período, entre 1995 e 1996, para consultar a comunidade acadêmica e construir a versão preliminar; e o baixo retorno dessa comunidade acadêmica, apenas 700 pareceres (se considerarmos todo o Brasil).

Antes mesmo de recorrermos aos autores que se debruçaram sobre o texto dos PCNs, já pode ser assinalado o pequeno grupo de educadores envolvidos e o curto espaço de tempo para a apreciação mais adequada da versão preliminar dos PCNs. 
Várias opiniões se manifestaram de forma crítica em relação ao processo de elaboração dos PCNs. Principalmente se o documento pretendia ser uma base comum nacional para o ensino fundamental, deveria ter contado com amplo processo de discussão na sua elaboração (Teixeira, 2000, p. 1).

Luiz Antônio Cunha, num texto recente, faz referência à época:

Os PCN foram elaborados logo ao início da gestão de Paulo Renato Sousa [sic] no Ministério da Educação (1995-2002). O projeto contou com a participação de professores de uma escola privada de São Paulo, reuniu numerosos assessores e recorreu à consultoria de César Coll, especialista espanhol em questões curriculares, inspirador da reforma educacional de seu país natal (...).

[Em outro momento] reclamei da pressa no processo de elaboração, do descarte da colaboração institucional das universidades e institutos de pesquisa, assim como da desconsideração para com o grande esforço de construção curricular que vinha sendo desenvolvido, havia anos, em vários estados e municípios, esforço esse que foi atropelado pelo MEC (Cunha, 2009, p. 405).

A própria criação dos PCNs rompeu com a sua proposta de construção de uma cidadania democrática. E isso se agrava ainda mais quando nos referimos especificamente aos 'temas transversais'. Estes deveriam ter sido amplamente debatidos, 10 desenvolvidos até para além dos educadores e pesquisadores em educação, mas nem esses se sentiram contemplados ou minimamente representados.

\section{Os PCNs pegaram! E especificamente os temas transversais?}

Paradoxalmente, apesar do início controverso dos temas transversais, os PCNs se firmaram. Eles foram e ainda são citados por numerosos documentos, continuam a ser referência para os livros didáticos e para as atuais orientações curriculares e estão presentes nos projetos políticos-pedagógicos (PPPs) das escolas, como veremos mais adiante. Por que isso aconteceu? Uma hipótese é que, embora não tenham sido construídos democraticamente, tenham atingido, mesmo que parcialmente, algumas demandas sociais. A origem autoritária questiona a sua legitimidade, mas não chega a impedir que eles se estabeleçam.11

Os PCNs atingiram mais as escolas do que as Diretrizes Curriculares Nacionais (DCNs), quando deveria ser o contrário, uma vez que aqueles seriam apenas referências, parâmetros, como o próprio nome já diz. Ao menos no início, as DCNs não conquistaram a mesma dimensão que os PCNs. Isso pode ser visto no trabalho de Bonamino e Martínez (2002), que afirmam haver, 
como pano de fundo dos PCNs e das DCNs, uma divergência política entre o MEC e o Conselho Nacional de Educação (CNE).

A análise da forma de encaminhamento e do teor da proposta curricular enviada pelo MEC ao CNE deixa claro que se tratou de uma política construída num movimento invertido, no qual os PCNs, apesar de serem instrumentos normativos de caráter mais específico, deveriam reorientar um instrumento de caráter mais geral como as DCNs.

(...) Na lógica do MEC, mais importante do que inscrever a discussão das diretrizes curriculares na agenda política do Estado ou no debate público, era ver rapidamente os PCNs aprovados pelo CNE e efetivados pelos professores nas redes de ensino (Bonamino e Martínez, 2002, p. 372).

Na ocasião, o MEC submeteu ao CNE, que seria o órgão responsável pela construção das diretrizes curriculares que balizariam os currículos das escolas do país. A urgência do MEC em aprovar os PCNs tinha a intenção de obter tal status. De imediato, essa 'queda de braço' resultou numa negligência de mão dupla: os documentos não se complementaram e, mais do que isso, se distanciaram. Essa inversão teve como resultado a caracterização das DCNs como o documento mais distante e a presença bem maior dos PCNs nas escolas (embora nem fossem obrigatórios).

\section{De onde e sobre o que falamos}

Antes da continuação da análise, vale explicar nossa perspectiva e nosso recorte. O estudo que aqui vai sendo apresentado foi realizando coletivamente no Grupo de Pesquisa em Trabalho-Educação e Educação Ambiental (GPTEEA) do Instituto Federal de Educação, Ciência e Tecnologia do Rio de Janeiro (IFRJ), e corresponde a uma expectativa dentro de um grande projeto: “As intersecções dos temas saúde e ambiente no ensino formal: análise das práticas docentes e materiais didáticos", apoiado pelo Programa de Apoio a Grupos Emergentes de Pesquisa no Estado do Rio de Janeiro, da Fundação Carlos Chagas Filho de Amparo à Pesquisa do Estado do Rio de Janeiro (Faperj). Esse projeto deu solidez ao Programa de Pós-Graduação Stricto Sensu em Ensino de Ciências (Propec) do IFRJ.

O GPTEEA ficou responsável por estudar os documentos oficiais da educação básica que tratam dos temas transversais meio ambiente e saúde, assim como o reflexo de tais temas nos documentos constituídos pelas próprias escolas - no caso, preferencialmente os PPPs. As escolas estudadas localizavam-se na Baixada Fluminense, foco do Programa de Apoio a Grupos Emergentes de Pesquisa no Estado do Rio de Janeiro12 já mencionado. 
Tendo como pano de fundo nossas leituras sobre os temas saúde (Candeias, 1997; Scherer et al., 2005; Santos e Westphal, 1999; Pontes e Schramm, 2004) e meio ambiente (Bomfim, 2010; Bomfim e Piccolo, 2009; Chesnais e Serfati, 2003; Deluiz e Novicki, 2004; Foladori, 2001; Foster, 2005; Layrargues, 1997; Löwy, 2005; Sobral, 1997), fomos aos PCNs, às DCNs, aos PPPs das escolas e às OCEMs (Brasil, 2006a, 2006b, 2006c). Além do conteúdo, procurou-se analisar a abordagem, o formato, o material e, principalmente, os intelectuais orgânicos envolvidos. Não obstante terem sido tomados todos os cuidados para não se produzir uma leitura muito e evidentemente enviesada, mas também pressupondo que teríamos uma leitura particular, pois isso é inescapável, "cada material de análise exige que seu analista, de acordo com a questão que formula, mobilize conceitos que outro analista não mobilizaria, face a suas (outras) questões"' (Orlandi, 2005, p. 27).

Uma das formas para amenizar os excessos na interpretação de um texto foi realizar a sua leitura coletivamente, porém sem cair na ingenuidade de desconsiderar que "a memória é seletiva, a lembrança diz respeito ao passado, mas se atualiza sempre a partir de um ponto do presente" (Goldenberg, 2003, p. 53). Não podemos exigir do texto mais do que seu contexto histórico pode dar; também não há como evitar nossa leitura a partir do hoje e de nossas atuais necessidades.

Os PCNs foram publicados em 1997, influenciados pelo 'modelo de competências', 13 termo trabalhado por Deluiz (2001), entre outros autores, como crítica à 'Pedagogia das Competências' (Ramos, 2001). O corpo técnico do MEC se esmerou em colocar rapidamente os PCNs nas escolas, antes mesmo das DCNs (Bonamino e Martínez, 2002). Essa foi uma característica emblemática dos PCNs: os 'intelectuais' orgânicos que na verdade estiveram por trás do documento não eram pesquisadores ou acadêmicos das principais universidades e institutos de pesquisa em educação do país. Quem assina o documento são pesquisadores menos experientes com titulação incipiente, pelo menos na época (alguns funcionários do MEC). ${ }^{14}$ Ainda que o próprio documento faça referência à Fundação Carlos Chagas (Brasil, 1997a) e também a outros renomados consultores, 15 estes sim, pesquisadores seniores, os PCNs tiveram essa peculiaridade em sua construção, se comparamos, por exemplo, com as DCNs. E como vimos, o processamento aligeirado do documento resultou em pouca participação efetiva da comunidade acadêmica na sua elaboração. Esta inferência se confirmou quando em comparação com as OCEMs (Brasil, 2006a, 2006b, 2006c), que obtiveram maior participação dos pesquisadores em educação diretamente no texto.

As principais críticas apontavam os PCNs voltados ao modelo de competências como submetidos ao imediatismo do mercado de trabalho e ao produtivismo (Lopes, 2001), assim como subordinados acriticamente às indicações de organismos internacionais (Fonseca, 1998; Altmann, 2002; 
Frigotto e Ciavatta, 2003), características marcantes da chamada Reforma Educacional da década de 1990 (Shiroma, Moraes e Evangelista, 2002). No período seguinte, já no governo do presidente Luiz Inácio Lula da Silva, houve alguns movimentos de ruptura, embora não se tenha efetivamente rompido com muitas das políticas anteriores (Melo, 2006). A permanência dessa influência nos documentos da década de 1990 é uma das justificativas deste estudo.

\section{Uma década e meia de PCNs e temas transversais: exercitando uma reavaliação}

Ao considerarmos o documento de introdução aos PCNs e seus temas transversais (Brasil, 1997a) como ponto de partida, pode-se dizer que estamos próximos de uma década e meia com a proposta de transversalidade. É um momento interessante para uma reavaliação. 16 Destarte, sem desconsiderar a farta bibliografia a respeito, fiquemos em nosso foco: os temas 'meio ambiente' e 'saúde'.

\section{Revisitando o 'meio ambiente' dos PCNs: muito texto, pouca transversalidade}

No documento (Brasil, 1998d), não é possível identificar se há autores específicos para o texto-base da parte sobre meio ambiente, pois só há a 'ficha técnica' no final, em que aparecem os elaboradores, consultores e assessores sem especificar para que função. Já as referências bibliográficas se apresentam diferentemente, pois estão separadas por tema transversal. Por sinal, uma bibliografia bem diversificada, de vários autores importantes da área de educação ambiental (EA) - considerando-se a época, certamente -, incluindo legislação ambiental, documentos dos eventos internacionais e também de organismos e comissões sobre meio ambiente (Brasil, 1998d). Os textos de EA aparecem em bom número em relação aos outros que tratam da 'questão ambiental' na ótica da ecologia, da filosofia, da economia, do direito ou da geopolítica.

O conteúdo em si da parte sobre meio ambiente é razoável nos PCNs pelos seguintes motivos: percebe o problema ambiental como sendo um problema humano (antrópico); questiona o uso de recursos não-renováveis, atenta para as unidades de conservação, incentiva pesquisa na área ambiental; apresenta os problemas sociais e das populações humanas como sendo também ambientais; faz referência aos eventos internacionais que promovem a realização de acordos e encaminhamentos políticos; apesar de ficar no limite do desenvolvimento sustentável, problematiza pontos de divergência relativos às concepções sobre a relação homem-natureza e políticas ambien- 
tais; mesmo que brevemente, questiona o consumismo da atual sociedade, indo um pouco além da EA restrita à reciclagem e mitigação dos resíduos; e promove a EA.

No entanto, o conteúdo apresenta elementos que podem ser vistos ora como atrasos, ora como superficiais, ora como ineficazes para o tratamento da problemática ambiental. Algumas dessas características referem-se não somente ao que diz respeito ao meio ambiente, mas aos próprios PCNs. Os pontos relacionados a seguir resultaram de nossos estudos coletivos, auxiliados pelas nossas leituras que procuraram constituir uma 'educação ambiental crítica'. Procuramos relacionar os elementos mais gerais e evidentes, mesmo porque não tínhamos a expectativa de encontrar um texto de vanguarda num documento oficial, produzido na década neoliberal.17 É importante ir para além do próprio conteúdo do texto, conforme nos diz Kosik:

(...) o texto pode desenvolver e desempenhar várias funções nas quais o seu elemento específico não está presente. (...) Pode-se incluir na história das ideologias[:] dramas, poesias, romances e novelas, abstrair-se da especificidade do seu gênero e examiná-los exclusivamente como manifestações de concepções do mundo (Kosik, 1976, p. 144).

Embora o texto-base ofereça uma razoável aproximação do tema ao docente, não consegue oferecer elementos mais concretos ou mais palpáveis de aplicabilidade às diferentes áreas do conhecimento; não aponta recortes possíveis sobre como trabalhar com a temática; não dá as interfaces da EA com as disciplinas escolares; tem dificuldades de oferecer situações concretas de ação, inclusive para além das ações individuais, que deveriam também ser mais coletivas e promotoras do enfrentamento político; e não consegue indicar ou orientar atividades pedagógicas e culturais para o interior da escola e na relação com a comunidade para obtenção de mais conhecimento e mudanças efetivas no ambiente. E em relação ao conteúdo: não problematiza, não mostra como as diferentes classes sociais possuem responsabilidades e sofrem desigualmente as mazelas da degradação ambiental; não indica quem se beneficia com o incentivo ao consumismo e ao produtivismo; 18 não questiona (talvez não fosse possível alcançar naquele tempo) o impacto causado também pelos recursos renováveis, na busca insaciável da sociedade atual por energia; e não problematiza a relação homem e ambiente no tocante à vida nas cidades, limitando-se à perspectiva conservacionista (que só compreende essa relação com a delimitação de territórios).

Analisando as fotos que acompanham o texto, 19 obtemos inferências interessantes. As fotos são assinadas apenas por dois autores: Zysman Neiman (cinto fotos) e Iolanda Huzak (duas). Desse modo, o documento perdeu uma boa oportunidade de diversificar cenários, obter imagens vindas de varia- 
das regiões do país e de diversos autores (apenas duas fotos não vieram assinadas). Zysman Neiman (na ficha técnica do documento) foi apresentado como elaborador dos PCNs, e Iolanda Huzak como assessora. Esta é fotógrafa e jornalista profissional. Neiman foi um dos redatores do texto-base do tema transversal meio ambiente. As fotos são principalmente de paisagens naturais, semiárido, rios e matas, Pantanal. A presença do homem está associada a ambientes poluídos (duas fotos); a educação ambiental está representada numa imagem sobre reciclagem na escola e numa turma com livros e cadernos ao ar livre... Destarte, as fotos se apresentaram ainda menos avançadas que o texto, não ou pouco instigam novas reflexões, ficam na perspectiva conservacionista, separam o homem da natureza e reduzem a ação ambientalista à reciclagem. Perdeu-se a oportunidade de questionar o consumismo, o produtivismo, as diferentes ações poluidoras, a degradação mais local e global etc. E reforçou-se a ideia de que o melhor para homem e natureza é se manterem afastados (divórcio). Numa das fotos, crianças brincam num rio com muito verde em volta, sugerindo um lazer eventual. Assim se dá a relação entre homem e natureza nos PCNs!

Essas poucas fotos também acabam por revelar uma característica importante dos PCNs: a preferência por um texto longo, com poucas imagens, poucas sugestões lúdicas para atrair o leitor e servir de subsídio aos professores. E o mais grave: as fotos e as sugestões de dinâmicas não reproduzem (ou mesmo contradizem) o próprio texto que lhes dá a base.

A parte do meio ambiente termina com três anexos: um sobre os encontros internacionais de educação ambiental, o segundo sobre os princípios de Tbilisi e o último sobre os conceitos da problemática ambiental. A impressão geral é de que temos um texto tautológico, em que o conteúdo da educação ambiental fala dos princípios da educação ambiental em Tbilisi e outros encontros; e um texto que por sua vez precisa elucidar conceitos da área (disciplinarização?). A intenção inicial era de transversalidade, mas o texto não consegue fazer uma reflexão nessa direção.

\section{Revisitando a 'saúde' dos PCNs: a educação comportamentalista e como panaceia para a saúde?}

Com os mesmos procedimentos de estudo, utilizando como base uma literatura prévia e pertinente a essa temática, mas também sem ter como evitar a comparação com a parte do 'meio ambiente', abordamos o tema transversal 'saúde'.

Também para essa leitura fomos em busca de uma 'educação em saúde crítica', contrapondo-se exatamente a uma educação para a saúde que fosse conservadora, higienizadora, comportamentalista, filiada a uma tradição bem apontada por Morosini, Fonseca e Pereira (2009). 
E o que encontramos? Foi um texto mais confuso do que a parte do meio ambiente, com grandes dificuldades teóricas para a compreensão da relação 'saúde e educação'. É um texto que oscila muito, se contradiz.

Não obstante, comecemos com seus pontos mais avançados. O texto assume que se deve fazer uma 'educação para saúde' em vez de 'ensino de saúde', e que a prioridade não deve ser a doença, mas a prevenção. Critica em parte o 'biologismo' na educação para a saúde; considera importante a interface com alguns temas transversais (orientação sexual, por exemplo); diz que certas doenças acontecem por conta da estratificação social; não restringe saúde à questão de higiene e aponta a importância da alimentação adequada (desde que dialogue, sem arrogância, com uma determinada cultura alimentar). Também traz um alerta para a questão das drogas (ilícitas) e reforça o combate ao álcool e ao tabaco (lícitas). Agora vamos ao que consideramos lacunas, contradições ou aporias no texto-base sobre saúde.

Embora o texto-base comece dizendo que uma doença como a tuberculose, por exemplo, tenha questões sociais implícitas, em outros momentos se contradiz ao afirmar que:

A área de Ciências Naturais, em especial, contempla conteúdos essenciais para a compreensão dos mecanismos biológicos que sustentam o fenômeno saúde/doença e exerce liderança na determinação do enfoque dado para a abordagem da vida humana (Brasil, 1998d, p. 275).

Independentemente de se reivindicar o protagonismo ou não da área das Ciências Naturais, a citação logo acima, ainda que não chegue a constituir uma contradição clara, no mínimo é um viés que não dá destaque à proposta de transversalidade. 20 Vai contra a proposta feita em outros momentos, em que o entendimento de saúde não deveria se restringir a uma perspectiva biologizante. Sobre as questões culturais, por exemplo, realmente pode ser oportuno problematizar mitos, crenças e concepções resistentes há séculos em determinados grupos sociais, mas a desmitificação e a 'desmistificação' não passam somente pelas ciências naturais. ${ }^{21} \mathrm{Na}$ verdade, é uma concepção muito antiquada e positivista; a ciência (agora, no sentido lato) já se distanciou há muito tempo dessa visão estreita, com a contribuição de abordagens interdisciplinares como propõe a ciência, tecnologia e sociedade (CTS) ou os ensinamentos da história da filosofia das ciências (HFC). O texto acima coloca, por exemplo, 'exercer a liderança', porém, como não confundir com uma imposição de hegemonia?

Inevitavelmente fomos fazendo a comparação entre as duas partes: 'meio ambiente' e 'saúde'. Em relação à primeira, apesar de nossas críticas, encontramos um texto-base razoável. Sobre a parte de 'saúde', observamos uma reflexão ainda incipiente, mesmo considerando a época, para se oferecer 
ao professor da educação básica. Independentemente do tamanho (porque a parte de meio ambiente tem o dobro de tamanho e o dobro de referências) (Brasil, 1998a), o que percebemos no texto-base 'saúde' foi também menos densidade. As referências bibliográficas, por exemplo, diversificaram-se pouco; os documentos de entidades governamentais e não-governamentais foram os que mais se destacaram. São apresentados poucos textos que efetivamente tratam a relação 'educação e saúde', o que tem reflexo no texto, como continuaremos a mostrar.

As fotos que aparecem na parte de saúde foram assinadas apenas por Huzak. Mostram jovens se divertindo, fazendo dinâmicas, criança com dificuldades motoras participando de evento esportivo, ações de higiene (como a de uma moça lavando as mãos na escola), adolescentes fazendo cartazes para descarte adequado do lixo, crianças felizes próximas de um lavabo. Uma foto chamou a atenção talvez por seu conteúdo interdisciplinar, ao mos-trar um cultivo supostamente 'bombardeado' por agrotóxicos. Contudo, de forma semelhante à parte de meio ambiente, perdeu-se a oportunidade de diversificar as fotos, de oferecer uma visualização mais ampla. Certamente determinadas fotos não são apropriadas; também não tínhamos a expectativa de encontrar imagens que suscitassem mais críticas, mas algumas ficaram aquém do conteúdo sugerido pelo próprio texto. Seria interessante encontrar fotos que mostrassem a desigualdade social e a proliferação de vetores por conta da pobreza; problematizassem os tipos de alimentos; e indicassem reflexão sobre itens ligados à sexualidade (doenças sexualmente transmissíveis etc.).

Voltando ao texto-base, ele deixou lacunas em outros aspectos. O uso do álcool não é trabalhado de forma contundente na associação com os acidentes de trânsito. Na verdade, os acidentes de trânsito e a violência (os agentes externos) 22 foram pouco trabalhados. O texto deu destaque às drogas com um item específico, mas não deu a mesma atenção a outros itens importantes, como gravidez na adolescência e aborto, 23 assim como à questão das epidemias, por exemplo. Quanto às epidemias, a dengue já poderia ter sido mencionada, pois o documento de 1998 foi produzido após os primeiros grandes surtos de casos: 137.308 em 1995, 183.762 em 1996 e 249.239 em 1997 (em 1998 chegamos a 507.715) (Brasil, 2010).

Pode-se dizer que o texto toca em vários pontos, mas os aborda superficialmente, por vezes num pequeno parágrafo. Quando não é lacunar, é superficial. Outro assunto importante para reflexão em saúde é pensar a condição dos idosos. Embora o texto aborde a necessidade de os jovens estarem atentos às condições hereditárias de seus pais, para a prevenção de futuras doenças, perde a oportunidade de insistir em que vários outros hábitos na juventude podem garantir uma vida saudável na terceira idade. 
Como também de ressaltar, considerando a saúde na vida coletiva, que o cuidado com os idosos é um valor importante a ser assumido em educação. Apesar de uma das fotos mostrar um menino com dificuldades motoras, o texto não apresenta uma reflexão sobre acessibilidade (um item que ficou esquecido, de maneira geral, nos PCNs). De forma muito superficial, tocou na questão da obesidade e de que por conta dela se tomam muitos medicamentos emagrecedores. Nada sobre anorexia. Menciona a influência do ambiente (nesse momento, sugere a participação da geografia) nas questões da saúde, mas não associa substancialmente essa ideia à insalubridade do trabalho, às moradias inóspitas. Não relata de forma mais crítica o conceito de saúde e não estabelece as conexões com o termo à resiliência corporal.

De maneira geral, não tocar em um ou outro ponto na educação para saúde é compreensível, mas pode-se dizer agora que o texto-base da parte 'saúde' dos temas transversais (Brasil, 1998a) não tem profundidade, dá poucos elementos ao educador da educação básica e ainda traz os mesmos problemas das outras partes, dos outros temas transversais. Desse modo, também oferece poucos elementos para a trans e a interdisciplinaridade, indicando poucas pistas de ação. Tem visual pobre, sugere pouca ludicidade... Não opta por um campo metodológico que seja coerente com um texto construído com vistas à humanização da saúde. E o mais grave de tudo: segundo a nossa leitura, o texto-base tem implicitamente uma forte sugestão - a de que os problemas da saúde são resolvidos quase exclusivamente pela educação. O risco é uma manutenção de uma visão funcionalista de educação.

Embora o texto-base, em seu melhor momento, aponte a saúde como direito, não oferece ao educador os elementos para indicar as responsabilidades do Estado em relação às da sociedade. O que nos pareceu, na leitura de todo o texto, que o foco está sempre no indivíduo, na mudança de seu comportamento. O problema dessa perspectiva comportamentalista é a diminuição do aspecto político, porque também dessa forma a educação aparece como panaceia, redentora dos males sociais. Podemos ver isso em algumas passagens.

A Constituição de 1988 prevê, ainda, a implantação do Sistema Único de Saúde - SUS. O SUS tem caráter público, deve compreender uma rede de serviços regionalizada, hierarquizada e descentralizada, com direção única em cada esfera de governo (municipal, estadual e federal) e sob controle dos usuários por meio da participação popular nas Conferências e Conselhos de Saúde (Brasil, 1998a, p. 252).

O texto perde a oportunidade de problematizar o SUS, como também não incentiva o entendimento sobre o mecanismo de participação. A cidadania tão constantemente alardeada pelos PCNs não deveria ser passiva, precisaria 
ser ativa, combativa. E o texto deveria problematizar a participação do Estado, mas preferiu propor uma educação com o viés comportamentalista:

Durante a infância e a adolescência, épocas decisivas na construção de condutas, a escola passa a assumir papel destacado por sua potencialidade para o desenvolvimento e contínuo [sic]. Precisa, por isso, assumir explicitamente a responsabilidade pela educação para a saúde, já que a conformação de atitudes estará fortemente associada a valores que o professor e toda a comunidade escolar transmitirão inevitavelmente aos alunos durante o convívio cotidiano (Brasil, 1998a, p. 261).

A responsabilização da escola foi superdimensionada, segundo o texto, por uma exigência da sociedade:

Deve-se considerar também que, nas últimas décadas, além dos temas tradicionalmente trabalhados sobre saúde e nutrição, as questões biopsicossociais adquiriram maior visibilidade, e a escola foi compelida [a participar] - pelas circunstâncias e pelo reclamo da própria sociedade (...) (Brasil, 1998a, p. 262).

Não é que o texto-base não perceba o equívoco de apresentar toda a solução na mera transmissão de informação ou na prescrição de regras comportamentais, pois até chega a dizer que “a educação para saúde só será efetivamente contemplada se puder mobilizar para as mudanças na busca de uma vida saudável" (Brasil, 1998d, p. 262). O limite do texto é não dar um aspecto mais político à educação, mostrar que o imprescindível conhecimento precisa enfrentar o conflito de interesses e os impeditivos da própria materialidade. Por alguns momentos, o texto sugere que basta a educação, como se ela em si não estivesse subordinada à política, a interesses econômicos. Não obstante, vale saber que, muitas vezes, a compreensão não basta. Os alunos podem saber quais são os métodos contraceptivos, mas tem acesso a eles? Podem saber que a moradia é foco para vetores de várias doenças, mas isso permite a eles sair dessa moradia, da beira de um rio poluído? Sabem que as frutas possuem mais vitaminas, mas não são os alimentos processados os mais baratos? É possível abrir mão de um ambiente de trabalho insalubre quando se precisa dele?

Na verdade, o texto-base poupa demais o Estado. A 'educação para a saúde' aqui proposta não é problematizadora; perde todas as oportunidades de questionar as políticas públicas, de mostrar os interesses contrários à promoção da saúde etc. Pode-se dizer, nessa altura, que a proposta de cidadania (tão alardeada a todo momento nos PCNs) não é plena, alcança no máximo a compreensão do direito, mas não da luta por sua materialização. 


\section{PCNs e seus temas transversais promovem uma cidadania passiva? Algumas inferências}

O estudo das partes 'meio ambiente' e 'saúde', de maneira geral, indicou que o texto é pouco atraente, pouco prático, apresenta dificuldades em dar pistas de ação; não mostra bem as diferentes interfaces com as diferentes áreas; não facilita a visualização de como acontece a trans e a interdisciplinaridade. Em alguns momentos se apresenta lacunar ou superficial; e ainda que evidentemente o texto tenha de dar protagonismo à educação como resposta à questão social, o faz com uma proposta comportamentalista. Também ousa pouco (embora não pudéssemos esperar outra coisa), não supera o limite de crítica à própria sociedade. Por fim, foi percebido que a maior limitação do documento esteve no que mais alardeou desde a apresentação: “o compromisso com a construção da cidadania" (Brasil, 1998a, p. 17). Na verdade, o máximo que alcança é a promoção de uma cidadania passiva, limitada à compreensão do direito, mas longe de sua realização. Nesse limite, a educação serve mais à conformação do que à transformação da realidade; responsabiliza demasiadamente o indivíduo e isenta o Estado.

\section{Os PCNs e os outros documentos}

\section{PCNs e DCNs}

Na introdução, já havíamos apontado, com a contribuição de Bonamino e Martínez (2002), as divergências entre o MEC e o CNE em relação aos PCNs e às DCNs. O fato é que as DCNs do Ensino Fundamental (DCNEFs) chegaram depois (Brasil, 1998b), mas deveriam ter sido, pelo menos em tese, mais orientadoras, mais participantes em relação às escolas, mais influentes sobre os currículos do que os PCNs. Mesmo porque os PCNs, baseados no modelo de competências, vinham com o propósito de ser mais flexíveis, 24 mas o atraso das DCNs e o pouco apoio que receberam foram decisivos para diminuir sua influência. As DCNs citam os PCNs, mas o contrário não aconteceu (Brasil, 1998b). E o documento final, DCNs para o Ensino Fundamental, teve apenas duas páginas (Brasil, 1998c). Os papéis se inverteram; as DCNs ficaram mais flexíveis do que os PCNs.

Por fim, as DCNs do Ensino Fundamental só fizeram os apontamentos, estes deveriam ser incorporados pelas escolas e prováveis currículos. 'Saúde' e 'meio ambiente' foram sugeridos como outros itens da 'vida cidadã' (sexualidade, vida familiar e social, trabalho, ciência e tecnologia, cultura e linguagens), junto também das áreas de conhecimento (língua portuguesa, matemática, ciências, geografia, história, língua estrangeira, 
educação artística, educação religiosa) (Brasil, 1998c). As DCNs ficaram bem enxutas, não agregaram nenhuma reflexão a mais, não trabalharam os temas especificamente. E assim se constituiu mais um texto protocolar.

\section{PCNs e OCEMs}

Apenas com o intuito de complementar os estudos de revisita aos temas transversais, fomos também estudar as OCEMs. Por ser um documento também de orientação curricular e mais recente (Brasil, 2006a, 2006b, 2006c), tentamos fazer uma leitura que apreendesse o conteúdo tanto sobre 'meio ambiente' e 'saúde' (escopo deste trabalho) quanto sobre o possível legado dos PCNs. Vale alertar que é documento voltado ao Ensino Médio. Vamos às OCEMs.

As OCEMs estão na trilha de desenvolvimento das Diretrizes Curriculares Nacionais para o Ensino Médio (DCNEMs)25 (Brasil, 1998d), dos Parâmetros Curriculares Nacionais do Ensino Médio (PCNEMs) (Brasil, 1999, 2000) e dos PCNs + (Brasil, 2002a, 2002b, 2002c). E mostram realmente que houve uma evolução. O texto das OCEMs é superior aos primeiros momentos dos PCNs, da década de 1990.

As OCEMs tiveram a seu favor o legado dos documentos precedentes e também das críticas, podendo incorporar novas reflexões teóricas em educação. Dois aspectos também foram imprescindíveis para a melhora do texto: em primeiro lugar, houve mais tempo para a elaboração do documento; em segundo, obteve-se maior participação da comunidade acadêmica (Brasil, 2002a). Os trabalhos e iniciaram em 2004 e a publicação aconteceu em 2006. Os autores que assinam os textos-base são de centros de pesquisa com características mais sólidas e permanentes das universidades (Brasil, 2002a). Os textos-base, de maneira geral, não têm imagens, mas são menores e mais leves; em comparação com os primeiros PCNs, trabalham com quadros e informações mais breves. Também apresentam uma importante característica: oferecem numerosas pistas de ação para os professores.

As OCEMs se caracterizaram mais pela contribuição para a prática dos professores do que por lhes oferecer algum conteúdo novo ou específico. Indicaram em vários momentos quais seriam os conteúdos interessantes para se trabalhar no Ensino Médio; também propuseram novas abordagens e em alguns momentos até a supressão de conteúdos supérfluos. A interdisciplinaridade também é muito incentivada, assim como o debate e a busca da controvérsia.

As OCEMs das ciências da natureza, matemática e suas tecnologias, por exemplo, têm a preocupação de promover a 'alfabetização científica', estimulam o pensamento matemático, criticam o excesso de memorização.

Não obstante, mesmo um texto mais sofisticado como o das OCEMs pode avançar mais. O texto dos três livros (Brasil, 2002a, 2002b, 2002c) incentiva 
o tempo todo o debate, demonstrando que a ciência não é apolítica e não apresenta desenvolvimento linear. Mas essa qualidade de estimular o debate, quando oferece poucos elementos para aprofundá-lo, não é suficiente para a construção de conhecimento novo. Garantir, por exemplo, uma arena para os diferentes posicionamentos é importante, mas não certamente não é suficiente, pois pode até camuflar relações de dominação e conservadorismo. Por exemplo: a instauração de um debate sobre 'pena de morte' ou 'política de cotas', colocando em grau de equivalência, do início ao fim, os diferentes argumentos advindos dos alunos, pode apenas manter os posicionamentos iniciais ainda mais isolados e estanques.

Porém, o ponto que mais chamou a atenção foi a ausência da proposta de transversalidade nos documentos mais recentes. Os temas transversais e mesmo a proposta de transversalidade não vieram sendo discutidos da mesma forma como os conteúdos das disciplinas clássicas. O texto-base ainda escorrega em perspectivas bem fragmentadas, como se revela nessa passagem: “(...) compete ao ensino de Biologia, prioritariamente, o desenvolvimento de assuntos ligados à saúde, ao corpo humano, à adolescência e à sexualidade." (Brasil, 2002a, p. 25). A transversalidade se tornou obsoleta nos documentos em educação?

\section{Por que a transversalidade não entrou no século XXI?}

Agora, quase no fim deste estudo, vale a questão: por que os temas transversais não continuaram a se desenvolver nos documentos oficiais da área de educação?

Vimos que os temas 'meio ambiente' e 'saúde' tiveram força nos PCNs da década de 1990. Vimos também - e confirmaremos no próximo item - como são caros às escolas, correspondendo a temáticas prezadas pela sociedade. Na verdade, são temas sobre os quais não se para de refletir. Mas por que nos 'documentos oficiais em educação' não tiveram desenvolvimento?

Mesmo em estudos um pouco mais novos (Lomônaco, 2004), a referência é para os documentos da década anterior. O reconhecimento dos temas parece concreto, mas a transversalidade parece mesmo ter sido rejeitada, mal compreendida.

Verificamos que a concepção de transversalidade do tema está presente na escola, embora não se configure na prática, e a noção de interdisciplinaridade assemelhase mais ao conceito de multi ou pluridisciplinaridade, em que os trabalhos com mesmo conteúdo são realizados por diferentes professores, não existindo uma sistematização que produza um novo conhecimento ou uma integração de fato. Os conteúdos relacionados à saúde ainda são parte integrante do ensino de Ciências ou trabalhados pontualmente por meio de projetos (Lomônaco, 2004, p. 12). 
No final, a citação indica o que nos parece mais frequente: os temas transversais são trabalhados por meio de projetos. A princípio não é um problema, mas logo se torna, quando os temas são trabalhados exclusiva e eventualmente por projetos. Parece que a trans e a interdisciplinaridade não estão nos planejamentos, nos currículos, na interface com as disciplinas. Então podemos reiterar aqui, com relação aos estudos dos documentos oficiais da educação formal: os temas transversais ficaram na década de 1990 ! Os documentos mais novos não tratam dos temas, não há textos exclusivos nem textos que os evoquem substancialmente.

Para ilustrar, as OCEMs das ciências humanas mostraram residualmente possíveis interdisciplinaridades entre biologia e sociologia, ao mesmo tempo que o tema saúde ficou praticamente ausente; e só abordaram um pouco mais o tema ambiental quando atribuído à geografia (Brasil, 2002b). Nas OCEMs das ciências naturais e matemática, o tema saúde ficou com a biologia, estando ausente nas outras disciplinas; o mais espantoso foi o tema 'meio ambiente' ter ficado tão residual no documento inteiro (Brasil, 2002a). Nas OCEMs sobre linguagens e códigos, saúde só aparece em educação física, enquanto meio ambiente, num sentido que não se restrinja a qualquer espaço, é praticamente ausente (Brasil, 2002c). Não há transversalidade no documento!

Parece que assim ficou para as escolas: seus agentes tomam os temas para si, mas como não há documentos atualizados, recorrem aos da década de 1990.

\section{Os PCNs e os PPPs: uma aproximação}

A Lei de Diretrizes e Bases da Educação Nacional estabelece como uma das incumbências das escolas a elaboração de um projeto com propostas pedagógicas, com a garantia de participação dos profissionais de educação (Brasil, 1996). Só que em vez de se tornar a materialização de um ato democrático e participação no poder, o projeto político-pedagógico passou a ser mais uma das obrigações burocráticas que devem ser cumpridas pelas escolas.

Ao estudarmos os PPPs de algumas escolas, constatamos que os PCNs, mais do que qualquer outro documento, se fizeram presentes.

A maior parte dos PPPs não consegue demonstrar satisfatoriamente que eles foram constituídos num processo participativo na escola, na integração entre professores, alunos, direção, funcionários, pais e comunidade. Alguns deles também se apresentaram pouco densos, com pouca ou nenhuma referência e mínima reflexão. Outros se caracterizaram mais como um plano de tarefas.

O PPP da escola 'A'26 talvez seja o mais emblemático. Tem um texto elaborado às pressas, começa com a história da escola, depois a explicação de 
seu nome, apresenta a visão sobre alguns conceitos, não tem citação, não tem referência. O diagnóstico não traz uma pesquisa sequer, nem fonte. Isso acontece até no item denominado 'fundamentação teórica'. O PPP parece seguir um roteiro fixo, que atende aos preceitos governamentais e, assim, se constitui como 'educacionalmente' correto. O texto indica a construção do PPP somente por meio da entrega de um questionário a ser respondido pela comunidade escolar, mais nenhuma outra informação. Por fim, há um anexo, único exemplo de um projeto a ser realizado, sobre o tema 'ética e cidadania'; nele há a única citação de todo o documento: um trecho dos PCNs (na verdade, uma epígrafe).

O PPP da escola 'B' é bem mais denso. A curiosidade inicial é que segue o mesmo roteiro básico da escola 'A' (identificação, histórico, apresentação, diagnóstico, justificativa, missão, metas, objetivos, processo de construção, fundamentação teórica, estrutura e organização). As escolas parecem não desejar atualizar esse roteiro ou romper com ele. O texto faz uma contextualização melhor, embora com poucos dados e pesquisa. Tem fundamentação teórica, faz referência à LDB, a alguns autores importantes e aos PCNs e à Proposta de Reestruturação Curricular apresentada pela Secretaria de Educação do Estado. Não obstante, o próprio texto, ao mostrar o processo de construção do PPP, revelou que o documento prévio foi feito por uma única pessoa, o que evidencia seu caráter personalístico. Só após essa primeira etapa foi alcançada a participação da comunidade escolar, com a revisão do documento. A orientação curricular é muito incipiente, e em anexo aparece um exemplo muito superficial de projeto para a área de matemática.

O PPP da escola ' $C$ ' é de mais uma escola pública da Baixada Fluminense (como as duas anteriores), com mudanças apenas nas posições. Segue os itens do mesmo roteiro utilizado pelas escolas ' $A$ ' e ' $\mathrm{B}$ '. No diagnóstico da comunidade, também traz pouca pesquisa, incrementa com uma visão mais global, crítica ao capitalismo, mas fica (como o das outras escolas citadas), no senso comum de dizer que os alunos são de comunidades carentes, sem oferecer dados ou relatos de experiências mais precisos.27 A fundamentação teórica traz poucas referências. Os temas transversais apareceram somente nos projetos em anexo, o que mostra que nas discussões ocorridas para sua consecução não se fizeram presentes a apropriação nem a crítica dos conceitos.

A escola ' $\mathrm{D}$ ' também é pública, mas a única municipal. Apresentou o texto mais enxuto de todos, em que a característica generalista foi ainda maior. Na verdade, pode-se dizer que orienta pouco a própria escola; é um texto formal, que cita alguns autores sem profundidade, faz breve referência à LDB. Um texto burocrático e protocolar. 


\section{Considerações finais}

A revisita aos PCNs, especialmente aos temas transversais 'meio ambiente' e 'saúde', da década de 1990 tornou-se importante por dois motivos: primeiro, pela avaliação que se pôde fazer após a realização de um processo histórico; segundo, pela possibilidade de se obterem redirecionamentos e novas perspectivas. Essa revisita se justificou não somente pela relevância dos temas (que provavelmente se manterá por muitos anos), mas simplesmente porque não obteve, nos documentos oficiais, o desenvolvimento teórico que se observou na literatura pertinente às temáticas 'meio ambiente' e 'saúde'. Ainda que os PCNs, grosso modo, possam ter alcançado algum desenvolvimento (com os PCNs + , as OCEMs etc.), os temas transversais ficaram mesmo na década de 1990, e de lá orientam, superficialmente, os PPPs e eventos das escolas. A proposta de transversalidade é dispensada; os temas são reconhecidos sem serem problematizados; não se discute a possibilidade de novas metodologias, atividades, ou a incorporação de outros temas. Passou da hora de se rever os temas transversais. Nas escolas, continuam a ser apenas os motes para os eventos esporádicos do calendário anual, distribuídos de forma bem fragmentada com a liderança de poucos professores, cuja filiação a um tema está em consonância com a disciplina que ministram originalmente.

\section{Notas}

1 Professor adjunto do ensino superior de Sociologia da Educação do Instituto de Educação, Ciência e Tecnologia do Rio de Janeiro (IFRJ), Rio de Janeiro, Brasil. Doutor em Ciências Humanas-Educação pela Pontifícia Universidade Católica do Rio de Janeiro (PUC-Rio). $<$ alexandre.bomfim@ifrj.edu.br> Correspondência: Grupo de Pesquisa em Trabalho e Educação e Educação Ambiental (GPTEEA), Instituto Federal de Educação, Ciência e Tecnologia do Rio de Janeiro (IFRJ), Campus Nilópolis, Rua Lúcio Tavares, 1.045, CEP 26530-060, Centro, Nilópolis, Rio de Janeiro, Brasil.

2 Professora adjunta II do ensino superior do Instituto Federal de Educação, Ciência e Tecnologia do Rio de Janeiro (IFRJ), Rio de Janeiro, Brasil. Doutora em Desenvolvimento, Agricultura e Sociedade pela Universidade Federal Rural do Rio de Janeiro (UFRRJ). $<$ maylta@yahoo.com.br>

3 Professor de Geografia da Fundação de Apoio à Escola Técnica do Rio de Janeiro (Faetec-RJ) e da Prefeitura de Duque de Caxias, Rio de Janeiro, Brasil. Mestre em Ensino de Ciências pelo Instituto de Educação, Ciência e Tecnologia do Rio de Janeiro (IFRJ). $<$ mdougvini@gmail.com> 
4 Professora de Ciências da Prefeitura e do estado do Rio de Janeiro, Brasil. Mestre em Ensino de Ciência pelo Instituto de Educação, Ciência e Tecnologia do Rio de Janeiro (IFRJ). <simone.csmf@gmail.com>

5 Mestre em Ensino de Ciências pelo Instituto Federal de Educação, Ciência e Tecnologia do Rio de Janeiro (IFRJ), Rio de Janeiro, Brasil. <deniseaz@gmail.com>

6 Bolsista de Iniciação Científica, graduada em Ciências Biológicas pela Universidade do Grande Rio (Unigranrio), Duque de Caxias, Rio de Janeiro, Brasil. <carolluiza.castro@gmail.com>

7 No Brasil, o final da década de 1980 e o início da década de 1990 foram marcados por um conjunto de políticas aliadas a um "capitalismo transnacional oligopolista" e baseadas, sobretudo, na "desregulamentação dos mercados, na abertura comercial e financeira, na privatização do setor público e na redução do Estado” (Soares, 2001, p. 19).

8 Vale alertar, desde o início, que Orlandi (2005) não foi utilizada para constituir uma análise de discurso, o que requereria mais instrumentos, e sim para construir, junto com a análise de outros autores, uma leitura dos PCNs que pudesse superar minimamente qualquer superficialismo.

9 Intelectual orgânico, stricto sensu, é aquele ligado a uma das classes fundamentais: proletariado ou burguesia. Num sentido lato, nos referimos àqueles indivíduos ou instituições que se articulam para produzir hegemonia ou contra-hegemonia, inclusive para lutas e interesses de menor amplitude, como os interesses corporativistas. Recorremos a Gramsci, que "formula a distinção entre intelectuais como categoria orgânica de cada classe fundamental" (Manacorda, 1990, p. 151).

10 Cury também reivindicou mais tempo para a elaboração dos PCNs: “Daí a necessidade de que uma proposta concreta de Parâmetros Curriculares Nacionais seja encaminhada sem pressa e com diálogo" (Cury, 1996, p. 17).

$11 \mathrm{Na}$ verdade, esse é um aspecto peculiar ao Estado brasileiro, que mescla características democráticas e autoritárias em vários momentos e espaços (Oliveira, 2003).

12 Esse projeto Faperj já previa parceria com quatro escolas em Nilópolis, no entorno do IFRJ: Colégio Estadual Poeta Mário Quintana, Ciep Manoel Malaquias, Colégio Estadual Mario Campos e Instituto de Educação Carlos Pasquale. Foram estudadas duas dessas escolas e outras duas também da Baixada Fluminense. Porém, para a preservação das escolas, elas não serão identificadas no corpo do texto, mesmo porque a proposta aqui é de análise dos temas transversais nos PPPs e não exatamente das escolas.

13 Vale também conferir Lopes (2001) para a compreensão de como o modelo ou pedagogia das competências influenciou o currículo do ensino médio no período.

14 Esses autores foram apresentados no final do documento dos PCNs (Brasil, 1997a) na 'ficha técnica', no subitem "Elaboração".

15 Fica muito difícil qualificar ou hierarquizar a participação dos consultores, o quanto realmente se envolveram, qual o grau e o tipo de participação. Grosso modo, eram pesquisadores seniores, renomados, não exatamente em educação - alguns da área de linguagem, das ciências naturais, alguns estrangeiros (destaque para o espanhol César Coll Salvador). 
16 Ainda mais se considerarmos que já houve a experiência de dois governos, o de FHC e o de Lula.

17 Nos últimos anos, o debate ambiental ganhou novos contornos. Houve mais envolvimento da mídia, do cinema, das campanhas políticas etc. Também houve mais acordos, relatórios políticos e estudos científicos (ver, por exemplo, Intergovernmental Panel on Climate Change, 2007).

18 Provavelmente esse nível de crítica não era de se esperar, mas é importante marcar nossa perspectiva, para analisar o que o documento alcança e levando-se em conta que se trata de uma revisita a essa legislação e documentos sobre Educação, principalmente da década de 90 .

19 Não nos propomos a fazer aqui nenhum estudo mais aprofundado sobre as fotos um estudo iconográfico, por exemplo. Não obstante, queremos explorar as contradições mais evidentes em relação aos próprios textos dos PCNs, quando, por exemplo, ao se referir a uma educação ambiental menos comportamentalista ou fragmentada, uma foto mostra precisamente imagens do homem separado da natureza ou restrito à mitigação de resíduos.]

20 Eis a clássica fragmentação: para os professores de biologia vão os temas 'saúde', 'orientação sexual' e 'meio ambiente' (neste podem entrar os de geografia); para os de história e sociologia vão 'pluralidade cultural' e 'trabalho e consumo'; para os de filosofia, vai 'ética'...

21 A psicologia não tem nada a dizer sobre saúde, por exemplo? O processo educativo como algo a contribuir para a saúde, reivindicação do próprio PCNs, não é multidisciplinar por natureza? O protagonismo de uma área não vai depender das circunstâncias? Quais ações, por exemplo, são mais importantes em doenças que já possuem cura, como a tuberculose (para manter o mesmo exemplo do documento), as de políticas públicas ou as médicas?

22 Talvez o conceito de bullying, uma violência muito próxima da escola, não possa ser cobrado para aquele período, porque sua compreensão é mais recente (Palácios e Rego, 2006), mas vale chamar a atenção aqui como uma forma de revisão do texto.

23 Não estamos exigindo do texto, num tom messiânico, o que ele não pôde (por conta do contexto, por exemplo) ou não desejou oferecer. Mas pode-se exigir a partir dos próprios números do documento. O texto apontou, por exemplo, que $75 \%$ das mortes de homens jovens são de trânsito, homicídio ou suicídio. E para as jovens mães, em 1993 tivemos 15\% de mortes associadas à gravidez com meninas entre 10 e 19 anos (Brasil, 1998d).

24 "Por sua natureza aberta, configuram uma proposta flexível, a ser concretizada nas decisões regionais e locais sobre currículos e sobre programas de transformação da realidade educacional empreendidos pelas autoridades governamentais, pelas escolas e pelos professores. Não configuram, portanto, um modelo curricular homogêneo e impositivo, que se sobreporia à competência político-executiva dos Estados e Municípios, à diversidade sociocultural das diferentes regiões do País ou à autonomia de professores e equipes pedagógicas" (Brasil, 1997a, p. 13).

25 Diferentemente das DCNs do Ensino Fundamental (DCNEFs), as DCNs do Ensino Médio (DCNEMs) obtiveram um texto um pouco mais desenvolvido, mais orientador. Porém, o mais importante foi terem precedido os PCNs do Ensino Médio (PCNEMs) (Brasil, 1999, 2000). Desta vez os documentos não foram negligentes. 
26 Embora em nota anterior tenha acontecido a identificação parcial das escolas, achamos mais apropriado fazer a análise aqui sem explicitar a instituição, pois o escopo deste relatório de pesquisa são os documentos e não as escolas. Vale dizer que, das quatro escolas analisadas, duas são do Projeto Faperj.

27 Ainda que na pobreza muito se igualem os que nela estão inscritos, as condições sociais, econômicas, políticas e geográficas podem apresentar nuanças importantes a serem consideradas.

\section{Referências}

ALTMANN, Helena. Influências do Banco Mundial no projeto educacional brasileiro. Educação e Pesquisa, São Paulo, v. 28, n. 1, p. 77-89, jan.-jun. 2002.

BONAMINO, Alicia; MARTÍNEZ, Silvia Alícia. Diretrizes e Parâmetros Curriculares Nacionais para o Ensino Fundamental: a participação das instâncias políticas do Estado. Educação e Sociedade, Campinas, v. 23 , n. 80 , p. $368-385$, set. 2002.

BOMFIM, Alexandre Maia do. O (sub)desenvolvimento (in)sustentável: a questão ambiental nos países periféricos latino-americanos. Trabalho Necessário, Niterói, v. 8, n. 10, 2010. Disponível em: <www.uff.br/trabalhonecessario/images/ TN10BONFIM.pdf>. Acesso em: 4 set. 2012.

BOMFIM, Alexandre Maia do; PICCOLO, Fernanda Delvalhas. Educação ambiental crítica: para além do positivismo e aquém da metafísica. In: ENCONTRO NACIONAL DE PESQUISA EM ENSINO DE CIÊNCIAS (ENPEC), 7. Anais... Florianópolis: Associação Brasileira de Pesquisa em Educação em Ciências, 2009.

BRASIL. Lei de Diretrizes e Bases da Educação Nacional. Lei n. 9.9394, de 20 de dezembro de 1996. Brasília: Presidência da República, 1996. Disponível em: $<$ www.planalto.gov.br/ccivil_03/Leis/ L9394.htm>. Acesso em: out. 2010.
Ministério da Educação (MEC). Secretaria de Educação Fundamental (SEF). Parâmetros Curriculares Nacionais: introdução aos Parâmetros Curriculares Nacionais. Brasília, DF: MEC/SEF, 1997a.

Ministério da Educação (MEC). Secretaria de Educação Fundamental (SEF). Parâmetros Curriculares Nacionais: apresentação dos temas transversais, ética. Brasília, DF: MEC/SEF, 1997b.

Ministério da Educação (MEC). Conselho Nacional de Educação (CNE). Diretrizes Curriculares Nacionais para o Ensino Fundamental. Resolução n. 2, de 7 abril de 1998. Institui as Diretrizes Curriculares Nacionais para o Ensino Fundamental. Diário Oficial da União, Brasília, DF, 15 abr. 1998a. Disponível em: <http://portal.mec. gov.br/dmdocuments/resolucao_ceb_0298. pdf $>$. Acesso em: out. 2010.

Ministério da Educação (MEC). Conselho Nacional De Educação (CNE). Diretrizes Curriculares Nacionais para o Ensino Médio. Resolução CEB n. 3, de 26 de junho de 1998. Brasília, DF: MEC/CNE, 1998b. Disponível em: <http://portal.mec.gov.br/ cne/arquivos/pdf/rceb03_98.pdf $>$. Acesso em: out. 2010.

Ministério da Educação (MEC). Conselho Nacional de Educação (CNE). Câmara da Educação Básica (CEB). Parecer 
CEB n. 04/98. Diretrizes Curriculares $\mathrm{Na}$ cionais para o Ensino Fundamental. Brasília, DF: CEB/CNE, 1998c.

Ministério da Educação (MEC). Secretaria de Educação Fundamental (SEF). Parâmetros Curriculares Nacionais - terceiro e quarto ciclos: apresentação dos temas transversais. Brasília, DF: MEC/SEF, 1998d.

Ministério da Educação (MEC). Secretaria de Educação Média e Tecnológica (Semtec). Parâmetros Curriculares para o Ensino Médio. Brasília, DF: MEC/Semtec, 1999.

Ministério da Educação (MEC). Parâmetros Nacionais Curriculares Ensino Médio: bases legais. Brasília, DF: MEC, 2000. Disponível em: <http://portal.mec. gov.br/seb/arquivos/pdf/blegais.pdf $>$. Acesso em: out. 2010.

Ministério da Educação (MEC). Secretaria de Educação Média e Tecnológica (Semtec). $P C N+$ Ensino Médio: orientações complementares aos Parâmetros Curriculares Nacionais - ciências da natureza, matemática e suas tecnologias. Brasília, DF: MEC/Semtec, 2002a. Disponível em: <http://portal.mec.gov.br/seb/arquivos/pdf/ CienciasNatureza.pdf $>$. Acesso em: out. 2010.

Ministério da Educação (MEC). Secretaria de Educação Média e Tecnológica (Semtec). PCN + Ensino Médio: orientações complementares aos Parâmetros Curriculares Nacionais - ciências humanas e suas tecnologias. Brasília, DF: MEC/Semtec, 2002b. Disponível em: <http://portal.mec. gov.br/seb/arquivos/pdf/CienciasHumanas. pdf $>$. Acesso em: out. 2010.

Ministério da Educação (MEC). Secretaria de Educação Média e Tecnológica (Semtec). $P C N+$ Ensino Médio: orientações complementares aos Parâmetros Curriculares Nacionais - linguagens, códigos e suas tecnologias. Brasília, DF: MEC/Semtec, 2002c. Disponível em: <http://portal.mec. gov.br/seb/arquivos/pdf/linguagens02.pdf > . Acesso em: out. 2010.
Ministério da Educação (MEC). Secretaria de Educação Básica (SEB). Orientações curriculares para o ensino médio: linguagem, códigos e suas tecnologias. Brasília, DF: MEC/SEB, 2006a. v. 1.

Ministério da Educação (MEC). Secretaria de Educação Básica (SEB). Orientações curriculares para o ensino médio: ciências da natureza, matemática e suas tecnologias. Brasília, DF: MEC/SEB, 2006b. v. 2.

Ministério da Educação (MEC). Secretaria de Educação Básica (SEB). Orientações curriculares para o ensino médio: ciências humanas e suas tecnologias. Brasília, DF: MEC/SEB, 2006c. v. 3.

Ministério da Saúde. Casos de dengue. Brasil, grandes regiões e unidades federadas. 1997 a 2009. Brasília, DF: Ministério da Saúde, 2010. Disponível em: $<$ http://portal.saude.gov.br/portal/arquivos/ pdf/tab_casos_dengue_bra_gr_uf_97_09. pdf $>$. Acesso em: 4 set. 2012.

CANDEIAS, Nelly Martins Ferreira. Conceitos de educação e promoção em saúde. Revista Saúde Pública, São Paulo, v. 31, n. 2, p. 209-213, 1997.

CHESNAIS, François; SERFATI, Claude. 'Ecologia' e condições físicas de reprodução social: alguns fios condutores marxistas. Crítica Marxista, São Paulo, n. 16, p. 39-75, mar. 2003.

CUNHA, Luiz Antônio. A luta pela ética no ensino fundamental: religiosa ou laica? Cadernos de Pesquisa, São Paulo, v. 39, n. 137, p. 401-419, maio-ago. 2009. Disponível em: <www.scielo.br/pdf/cp/ v39n137/v39n137a05.pdf $>$. Acesso em: 4 set. 2012.

CURY, Carlos Roberto Jamil. Parâmetros Curriculares Nacionais e o ensino fundamental. Revista Brasileira de Educação, Rio de Janeiro, n. 2, p. 4-17, maio-ago. 1996. Disponível em: <www.anped.org.br/rbe/ rbedigital/rbde02/rbde02_03_carlos_roberto_ jamil_cury.pdf>. Acesso em: out. 2010. 
DELUIZ, Neise. O modelo de competências profissionais no mundo do trabalho e na educação: implicações para o currículo. Boletim Técnico do Senac, Rio de Janeiro, v. 27 , n. 3, set.-dez. 2001 .

DELUIZ, Neise; NOVICKI, Victor. Trabalho, meio ambiente e desenvolvimento sustentável: implicações para uma proposta de formação crítica. Boletim Técnico do Senac, Rio de Janeiro, v. 30, n. 2, p. 19-29, maioago. 2004.

FOLADORI, Guillermo. Limites do desenvolvimento sustentável. Campinas: Editora da Unicamp, 2001.

FONSECA, Marília. O Banco Mundial como referência para a justiça social no Terceiro Mundo: evidências do caso brasileiro. Revista da Faculdade de Educação, São Paulo, v. 24, n. 1, p. 37-69, jan.-jun. 1998.

FOSTER, John Bellamy. A ecologia de Marx: materialismo e natureza. Rio de Janeiro: Civilização Brasileira, 2005.

FRIGOTTO, Gaudêncio; CIAVATTA, Maria. Educação básica no Brasil na década de 1990: subordinação ativa e consentida à lógica do mercado. Educação e Sociedade, Campinas, v. 24, n. 82, p. 93-130, abr. 2003.

GOLDENBERG, Mirian. A arte de pesquisar: como fazer pesquisa qualitativa em ciências sociais. 7. ed. Rio de Janeiro: Record, 2003.

GRAMSCI, Antonio. Concepção dialética da História. Rio de Janeiro: Civilização Brasileira, 1981.

INTERGOVERNMENTAL PANEL ON CLIMATE CHANGE (IPCC). Climate Change 2007. Paris: IPCC, fev. 2007. Disponível em: $<$ www.ipcc.ch>. Acesso em: 28 fev. 2007.

KOSIK, Karel. Dialética do concreto. 2. ed. Rio de Janeiro: Paz e Terra, 1976.

LAYRARGUES, Philippe Pomier. Do ecodesenvolvimento ao desenvolvimento susten- tável: evolução de um conceito? Proposta, Rio de Janeiro, v. 24, n. 71, p. 1-5, fev. 1997.

LOMÔNACO, Aparecida de Fátima Soane. Concepções de saúde e cotidiano escolar - o viés do saber e da prática. In: REUNIÃO DA ASSOCIAÇÃO NACIONAL DE PÓS-GRADUAÇÃO E PESQUISA EM EDUCAÇÃO (ANPED), 27. Caxambu: Anped, 2004. Disponível em: <www.anped.org.br/reunioes/ 27/gt06/t063.pdf>. Acesso em: out. 2010.

LOPES, Alice Casimiro. Competências na organização curricular da reforma do ensino médio. Boletim Técnico do Senac, Rio de Janeiro, v. 27, n. 3, set.-dez. 2001.

LÖWY, Michael. Ecologia e socialismo. São Paulo: Cortez, 2005.

MAINGUENEAU, Dominique. Novas tendências em análise do discurso. 3. ed. Campinas: Editora da Unicamp, 1997.

MANACORDA, Mario. O principio educativo em Gramsci. Porto Alegre: Artes Médicas, 1990 .

MELO, Savana Diniz Gomes. Continuidade e/ou rupturas nas políticas para o ensino médio e educação profissional. In: REUNIÃO DA ASSOCIAÇÃO NACIONAL DE PÓS-GRADUAÇÃO E PESQUISA EM EDUCAÇÃO (ANPED), 29. Caxambu: Anped, 2006. Disponível em: <www.anped.org.br/reunioes/ 29ra/trabalhos/trabalho/GT05-2016--Int.pdf>. Acesso em: nov. 2010.

MOROSINI, Márcia Valéria; FONSECA, Angélica Ferreira; PEREIRA, Isabel Brasil. Educação em saúde. In: PEREIRA, Isabel Brasil; LIMA, Julio César França (Orgs.). Dicionário da educação profissional em saúde. 2. ed. rev. e ampl. Rio de Janeiro: Escola Politécnica de Saúde Joaquim Venâncio, 2009. p. 155-162. Disponível em: <www.epsjv. fiocruz.br/dicionario/verbetes/edusau.html>. Acesso em: 4 set. 2012

OLIVEIRA, Francisco de. Crítica à razão dualista/O ornitorrinco. São Paulo: Boitempo, 2003. 
ORLANDI, Eni. Análise do discurso: princípios e procedimentos. 6. ed. Campinas: Pontes, 2005.

PALÁCIOS, Marisa; REGO, Sérgio. Bullying: mais uma epidemia invisível. Revista Brasileira de Educação Médica, Rio de Janeiro, v. 30, n. 1, p. 3-5, jan.-abr. 2006.

PONTES, Carlos Antonio Alves.; SCHRAMM, Fermin Roland. Bioética da proteção e papel do Estado: problemas morais no acesso desigual à água potável. Cadernos de Saúde Pública, Rio de Janeiro, v. 20, n. 5, p. 1.3191.327, set.-out. 2004.

RAMOS, M. A pedagogia das competências e a psicologização das questões sociais. Boletim Técnico do Senac, Rio de Janeiro, v. 27 , n. 3, set.-dez. 2001 .

RIO DE JANEIRO. Secretaria de Estado de Educação (SEE). Livro II-Ciências da Natureza e Matemática. Rio de Janeiro: SEE, 2006.

SANTOS, Jair Lício Ferreira; WESTPHAL, Marcia Faria Práticas emergentes de um novo paradigma de saúde: o papel da universidade. Estudos Avançados, São Paulo, v. 13, n. 35, p. 71-88, jan.-abr. 1999.

SAVIANI, Dermeval. A nova lei da educação - $L D B$ : trajetórias, limites e perspectivas. São Paulo: Autores Associados, 1997.
SCHERER, Magda Duarte dos Anjos et al. Rupturas e resoluções no modelo de atenção à saúde: reflexões sobre a Estratégia Saúde da Família com base nas categorias kuhnianas. Interface - Comunicação, Saúde, Educação, Botucatu, v. 9, n. 16, p. 53-66, set. 2004-fev. 2005.

SHIROMA, Eneida Oto; MORAES, Maria Célia; EVANGELISTA, Olinda. Política educacional. 2. ed. Rio de Janeiro: DP\&A, 2002.

SOARES, Laura Tavares Ribeiro. Ajuste neoliberal e desajuste social na América Latina. Petrópolis: Vozes, 2001.

SOBRAL, Helena Robeiro Globalização e meio ambiente. In: DOWBOR, Ladislau; IANNI, Octávio; RESENDE, Paulo Edgar. (Orgs.). Desafios da globalização. 3. ed. Petrópolis: Vozes, 1997. p. 140-146.

TEIXEIRA, Beatriz de Basto. Parâmetros Curriculares Nacionais, Plano Nacional de Educação e a autonomia da escola. In: REUNIÃO DA ASSOCIAÇÃO NACIONAL DE PÓS-GRADUAÇÃO E PESQUISA EM EDUCAÇÃO (ANPED), 23. Caxambu: Anped, 2000. Disponível em: <www.anped.org.br/ reunioes/23/textos/0503t.PDF $>$. Acesso em: 4 set. 2012.

Recebido em 17/05/2011

Aprovado em 19/10/2011 